University of Nebraska - Lincoln

DigitalCommons@University of Nebraska - Lincoln

Faculty Publications: Department of Teaching, Department of Teaching, Learning and Teacher Learning and Teacher Education

2021

\title{
Teaching and Learning News Media in Politically Unsettled Times
}

H. James Garrett

Mardi Schmeichel

Joseph McAnulty

Sonia Janis

Follow this and additional works at: https://digitalcommons.unl.edu/teachlearnfacpub

Part of the Curriculum and Instruction Commons, Journalism Studies Commons, Mass

Communication Commons, Social Media Commons, and the Teacher Education and Professional

Development Commons

This Article is brought to you for free and open access by the Department of Teaching, Learning and Teacher Education at DigitalCommons@University of Nebraska - Lincoln. It has been accepted for inclusion in Faculty Publications: Department of Teaching, Learning and Teacher Education by an authorized administrator of DigitalCommons@University of Nebraska - Lincoln. 


\title{
Teaching and Learning News Media in Politically Unsettled Times
}

\author{
H. James Garrett, Mardi Schmeichel, Joseph McAnulty, and Sonia Janis
}

Educational Theory and Practice, University of Georgia, Athens, Georgia, USA

Corresponding author - H. James Garrett, email hjames@uga.edu

\begin{abstract}
Our research explores and elaborates the ways preservice teachers come to know and begin conceptualizing ways of teaching about news media. We report on what we interpret as their understandings and, perhaps more importantly, their misunderstandings of media literacy as they relate to their emerging ideas about what it means to teach others about crucial social and political issues of our time. The students with whom the authors worked demonstrated problematic misperceptions and misunderstandings about important media concepts and topics. These preservice teachers misunderstood the ways in which news media is different from other media genres. Additionally, they often indicated that avoiding bias on an issue required the consideration of two competing and equally worthy sides, even in the cases of extremely biased or false stories. We discuss the implications of these misunderstandings as simultaneously raising the stakes for teacher educators as well as calling attention to the limits of teacher education in relation to future teachers' knowledge of (in this case) news media.
\end{abstract}

Keywords: teacher education, social studies education, media literacy, complexity theory

\section{Introduction}

Continued global fracturing of the media landscape, the ubiquity of social media networking, and the rise to prominence of partisan blog/news sites have elevated the call for news media education. As the media landscape fractures, consumers have exponentially greater numbers of ways to access what is experienced as "news." Foreign governments use social media with sophisticated targeting to disrupt democratic processes. These changes have 
recently been accompanied by attacks on major media outlets by the current US president and his administration, including threats of criminal prosecution of reporters doing their jobs. Further complicating this landscape are numerous studies and analyses (e.g., Iyengar \& Hahn, 2009; Pariser, 2011; Sunstein, 2007) indicating that digital media consumption contributes to the production of echo chambers and filter bubbles that expose users to news that aligns with their preexisting understandings and beliefs.

Social studies teachers are not immune, of course, from such predominant cultural practices (Schmeichel et al., 2018). In light of rapidly changing media industries, along with the continuing amplification of bias, fake-news, post-truth, alternative facts, hyperpolarization (and the weaponization of each of these), understanding news media is an urgent priority for students (Journell, 2019). Therefore, each of these processes is related to crucial aspects of a teacher education that prepares educators to assist young people in effective participation in these rapidly shifting landscapes. They also raise confounding questions for teacher educators about how to introduce preservice teachers to key ideas and strategies from media education, particularly because introductions to media cannot be accurately thought of as introductions at all: the students have grown up in, and are normalized to, the ubiquitous cacophony of news and competitions for claims to truth (and lies).

In this article, we inquire into how preservice social studies teachers with whom we work understand news media and current sociopolitical issues as we made pedagogical invitations to develop those understandings in light of these above issues. The issues and topics described here emanate from our work as teacher educators within a college of education in a large research university in the southeastern United States. Specifically, this paper engages the question: What understandings about news media and pedagogy emerge in preservice social studies teachers' engagements with these topics in teacher education? To answer this question, we analyze students' work completed on assignments and through the lens of complexity theory.

Based on the analysis described in this article, we suspect that media education arrives too late if it arrives for the first time with one's teacher education. As preservice teachers return to the familiar and estranging spaces of classrooms, learning about news media is overridden with the intensities experienced in classrooms: there are too many new ideas all at once. Prevailing discourses about the media's untrustworthiness are powerful in shaping the sensibilities of preservice teachers, while pressures to remain neutral facilitate the uptake of false equivalence in their thinking about future teaching practices. Further, preservice teachers express the importance of investigating current events in their thinking about their work. However, they also exhibit problematic understandings that revert to the most popular and over-simplified understandings.

\section{Literature review}

\section{Truth decay and its consequences for civics education}

The "growing disregard for facts, data, and analysis" that forms the foundation of the problems discussed above is part of a phenomenon that has labeled truth decay (Kavanagh \& Rich, 2018, p. iii). Truth decay, as described by Kavanagh \& Rich is characterized by (1) skeptical interpretations of facts, (2) conflation of opinion and fact, (3) the proliferation 
of sources promoting opinion over fact, and (4) the erosion of trust in previously credible sources of factual information. All of these issues add up to a current civic situation that is in flux and in need of contextualizing, intervention, and theorizing. A growing body of research attends to these issues as we struggle as educators to help students understand the sociopolitical world and their relationship to it.

One way researchers are addressing these issues is to develop and assess materials for online civic reasoning. McGrew et al. (2018, p. 187) reported that, indeed, there is a need to develop curriculum that invites a more sophisticated and nuanced reading practice of online news sources. While many assume that "digital natives" may already have welldeveloped fluent practices online, what McGrew and her colleagues argue for are the necessity of skills around locating and assessing the quality and credibility of evidence found in online news sources. To investigate the state of practice, they developed assessments in which students were asked to determine quality, credibility, and bias in a variety of online situations. Their alarming finding is "that students struggled to engage in even basic evaluations of authors, sources, and evidence."

Jacobsen et al. (2018, p. 261) also investigated students' use of evidence as related to current issues represented in news media. Jacobsen et al. acknowledge that evidence is not the straightforward object that we may hope that it is. Indeed, in their observations of high school discussion groups, they observed students dismiss evidence and maintain the views they already held related to these particular issues. They conclude that we need to "develop a more nuanced approach [to evidence] that encourages students to be aware of their own emotional and positionality" in order to understand better how different people come to different conclusions about particular issues represented in news media.

The idea that evidence should be considered in relation to prior beliefs and the ways those beliefs resist shifting is an important item to consider in the context of news media literacy. Motivated reasoning is the term given by political psychologists to identify the process by which people will dismiss evidence that runs counter to their prior beliefs. Kahne and Bowyer $(2017$, p. 3) explored the phenomenon of motivated reasoning in terms of citizenship education. Their study used a large data sample to find out whether educational attainment and experience influenced the ability of people to evaluate truth claims. What they found, perhaps counterintuitively, is that increased "political knowledge did not improve judgments of accuracy [of claims related to controversial public issues]." We wish to underscore the significance of this finding because it points to a need to address issues of civic importance not only on the level of the content-the "what" of learningbut also the "how" of learning, or how information is taken up into the already circulating modes of understanding and what that means for civic decision making (Garrett, 2017).

However, Kahne and Bowyer (2017) findings do indicate students need specific and robust attention to media education and media literacy, and that participants in their study who had received some media education were less likely to engage in motivated reasoning. This research provides an urgent and compelling amplification of the continued call for, and focus on media education. While many countries have required media education for years, the United States lags in mandating media literacy in its formal curriculum. 


\section{Media literacy in teacher education}

Our review of research on preservice teachers' media literacy revealed that attention to media education in teacher preparation programs has been sparse but is an important area of focus. Damico and Panos (2018) suggest that working with preservice teachers to identify and articulate their beliefs in conjunction with media source analysis and group discussion is a promising way to increase sophisticated media literacy practices. However, Meehan et al. (2015) assert that despite calls to incorporate media literacy education into teacher education, few programs include it. Echoing the work of Stoddard (2014, p. 85), they note that because accreditation policies and bodies do not require media literacy, and because media literacy is not addressed explicitly in the common core, teacher education programs have not been compelled to include it. Despite these constraints, the authors describe the importance of including media literacy in teacher education and identify specific ways they enacted this content in their own teacher education program, including a social studies method class, arguing that it can "fit into the traditional curriculum and coursework the preservice teachers are already required to take."

Similarly, Stein and Prewett (2009), called for the inclusion of media literacy education in teachers' professional development experiences, noting that media shapes "attitudes and opinions about history, government, and politics" and that as such, "media literacy education in social studies can promote student understanding and appreciation of the role media play in shaping and disseminating particular views of the world" (p. 132). They surveyed social studies teachers interested in implementing media literacy education and found that despite the teachers' understanding of the importance of media education in the discipline, many lacked the confidence to analyze media. These authors conclude that although teachers' "motivation to teach media literacy education is high ... they feel inadequately prepared to do so" (p. 141).

While the limited number of studies describing preservice teachers' experience of media education focused on broad notions of media literacy, our teacher education program focused exclusively on news media literacy, a subset of critical media literacy (Kellner \& Share, 2007). In critical media literacy, the goal is to understand media texts as connected to understandings of broader social and political processes, the politics of representations, and issues of power. News media, though, has specific importance in our current political landscape given the attacks on media credibility and the alarming phenomenon of "fake news" and associated terms like "post-truth" (Journell, 2019). In our work with preservice social studies teachers, we focused on issues specifically related to news media because of the direct connections to the sociopolitical upheaval in which we are all located. The stance toward social studies education that we foster in preservice teachers is that our discipline requires that we address the pressing issues of our time. We were, therefore, less focused on adhering to particular approach to media literacy (of which there are several) or set curricula and more focused on helping teacher candidates explore and imagine the complexities awaiting them in classrooms that have been instantiated by attacks on news media outlets' credibility. 


\section{Theoretical framework}

\section{Complexity as an approach to complex issues in teacher education}

We turned to complexity theory to make sense of what our preservice teachers were saying about learning about news media and news media literacy education. Cochran-Smith et al. (2014) argued for the necessity of complexity theory in education to produce new sets of questions and research projects within the field. They describe studies of complexity as being focused on dynamic systems, privileging disequilibrium, and focusing on emergence. Rather than research projects that seek to identify causal relationships intended for predictive use, research using complexity theory examines the emergence of meanings and articulations for the use of rethinking stances, practices, and structures of teacher education. For example, complexity theory invites us to consider the nested political, historical, social and economic factors that contribute to any educational outcome, and to trace the dynamics of the relationships between social forces, institutions, and individual actors. In this way, we are invited to understand our efforts in teacher education as something other than linear or predictable in their effects.

As Davis and Sumara (2006, p. 117) explain, something complicated, like a machine, can be reduced to its working parts. Something complex, like an organism or a learning community, is "more dynamic unpredictable, more alive." A complexity-oriented approach to thinking about news media and teacher education experiences focused on news media provides the context to articulate the dynamic interplay between the two. Complexity theory not only recognizes the interplay between systems and individual actors but recognizes individuals, their thoughts, actions, movements, and words as parts of the systems themselves (Davis \& Sumara, 1997). Specifically, complexity theory allows us to create the space to take into account the pervasive discourses about ideology, tribalism, government, and other institutions that were impossible to ignore in teacher candidates' perceptions, responses, and orientations toward media and teaching (Hetherington, 2013).

Thinking with complexity theory invites us to think about the ways that overlapping systems permeate our teacher education program. Gender, race, class, sexuality, and ability each are indicative of complex systems of identification that are themselves linked. Each of these systems is also linked with the systems that make up the idea of "truth decay" more generally. Further, the theory forces us to think about the presence of factors like accountability measures, our own backgrounds, and identities, and also things less "central" to typical classroom inquiry such as, for example, the local sports scene (often the source of students' energetic attention).

In other words, complexity theory focuses on features like unpredictability and disequilibrium within complex systems such as teacher education programs. These characteristics of teacher education systems ensure that the results of planning and practice are do not guarantee, in advance, any particular outcome. Despite our intention to teach preservice teachers how and why to include news media literacy in their future classrooms in meaningful ways, we cannot choose inputs to control particular outcomes. As political scientists have shown, peoples' investments in particular political positions will refuse or resist information contradictory to those positions. While ideas such as "motivated reasoning" certainly aid in accounting for how and why preservice teachers articulate their 
understandings of media, our use of complexity theory highlights that there is more than their investment in particular narratives and resistance to others at play in their work. Complexity theory allows us to acknowledge the significance of the simultaneity of that kind of political knowledge alongside the intellectual/emotional demands of learning to teach, their own histories of learning and relating to the world, the institutional contexts in which they find themselves, accountability regimes, and existing stances toward teaching. All contribute to the mishmash of classroom life, both in teacher education spaces and in their $\mathrm{K}-12$ practices, and complexity theory invites a consideration that these overlapping processes prevent us from making predictive claims.

However, this unpredictability does not let practitioners (or researchers) off the hook for engaging in thoughtful and purposeful curriculum and program design. Complexity theory recognizes variability and offers a framework that aligns with our deep commitments to tackling challenging issues in teacher education, while simultaneously acknowledging the impossibility of a grand solution to many challenges found in the development of teachers or in interventions into problematic thinking.

\section{Methods}

The issues and topics described here emanate from our work as teacher educators within a college of education in a large research university in the southeastern United States. Students in the social studies program in which we work pursue their initial certification in bachelor's or master's degree programs. The final year of the program involves a practicum semester and student teaching semester. Graduate and undergraduate students enroll in concurrent split level courses during this year of their program. In the practicum semester, students spend half of the term in middle school settings and half the term in high school settings. In the student teaching semester, preservice teachers work in one classroom for the entire term. Before the culminating year, the bachelor's and master's students take different courses that are designed to position students as knowledgeable about the field of social studies education and as novices in pedagogical methods. The program has, in recent years, focused on developing preservice teachers' capacities in three specific areas of social studies pedagogy: (1) connecting content to the world, (2) using evidence to make arguments, and (3) listening to and responding thoughtfully to students.

In light of the media education research presented earlier, and in response to current sociopolitical contexts, beginning in January 2017, we decided to add an additional focus to their courses. Media education, media literacy, news media, and pedagogies of current events, taken together, provide a theme of inquiry throughout the program upon which this particular research project builds. The group of students $(n=44)$ with whom we were working during this time were a mix of master's and undergraduate students (most between the ages of 20-30 years old) all working toward their initial certification. Twenty of the students self-identify as women, and only five students identify as people of color: three Latinx students, one multiracial student, and one African American student were all members of this group. Through an informal self-reporting of their news media habits, the students in our classes were similar to other groups of preservice teachers in that they were not confident in their awareness of current events (Journell, 2013). 
During the first week of the semester in which the data discussed below were generated, one of the research team members not involved in teaching that particular course presented the research opportunity to students in the class. Students who chose to participate signed consent forms that allowed us to use work produced in class as research data. What we have produced as data, then, are artifacts of students' thinking as codified through the specific genre of course assignments. When analyzing these utterances, and acknowledging these interactions as complex, we understand them as pieces of writing or recorded statements offered in response to an instructor's pedagogical demand, and therefore they must be understood as offered in such contexts. That is, we must greet these articulations with the fundamental assumption of what they are not: transparent windows into what the participant "actually thinks" or "actually knows." Methodologically, we continue to keep in mind that in the process of doing assignments, we are invoking a particular history and category of performance on the part of both the instructor (in the form of the demand, the assignment) and the student (in the form, manner, and quality) of their completion. Any time a teacher asks a student to write a paragraph or narrate an understanding, layered complexities are at play: the student's desire to please, to achieve, to make the grade, to express a thought, and the like. The constraints of coursework as data are important to acknowledge, but it is also important to note that students' assignments are a key source of information for teacher educators.

With these limitations and affordances in mind, we began our analysis by deidentifying assignments and loading them into qualitative research software as a clearinghouse for the varied student work. Regular research team meetings were held (and are ongoing) to discuss the patterns and issues that emerged from our focused reading of the data. These readings emerged in several different ways. One way we read data was in light of prior research done related to media literacy, by analyzing student work in the same way that Wineburg et al. (2016) analyzed student work. A second method of focusing our reading of data was to take seriously the intuited reflections of research team members involved in the teaching of the courses from which the data arose. That is, as pedagogues we hadthrough course discussions or in providing feedback on assignments-identified particular patterns or concerns that the research team would then read for not only on those specific assignments but across the emerging data set as a whole.

\section{Findings}

In this paper, we focus on one particularly significant feature that arose within the data we analyzed: the emergent misunderstandings and problematic knowledge presented as the students articulated their understandings through the class assignments. We consider how some of the students' articulations carry significance for the complexities inherent in learning and teaching about current social and political issues and how this learning happens through complex, mediated experiences and circulate through complicated networks and outlets. In what follows, we present and consider several excerpts from assignments completed by preservice social studies teachers as they engage in programmatic efforts to pre-

pare them to teach about and teach with news media and use complexity theory frame the 
clear and consistent patterns of misconceptions about crucial issues in media education and literacy.

\section{Misconception one: it's the media, man}

Widespread mistrust of media institutions is evident in larger sample surveys (e.g., Swift, 2016) and in the multiple assignments which provided students the opportunity to describe their understanding of the role of the media in society. The most concrete examples arose in students' responses to a January 2017 statement from US president Donald Trump. Course instructors asked students to respond to the following prompt:

Throughout his campaign, Trump critiqued the mainstream media. These critiques have continued during the transition and as President Trump has taken office. In the recent CIA speech, President Trump said the media were "among the most dishonest human beings on Earth." Do these critiques of the media by the President concern you? Why/why not?

In response to this statement, one student reported, "that the media has a way of twisting information and presenting it in a way that they see fitting or a way that they want us as Americans to construe it." Another wrote that "journalists and others working in media are almost always trained to spin stories and events in certain ways, or sell certain ideas or products." One student even based their interpretation of the quote based on lessons we had taught: "We know based off of the facts and based off of taking this class that fake media and fake news is a real thing and that it's coming on all and most of the news websites."

There are complex misunderstandings present in such articulations. On the one hand, we are supportive of the idea social studies teachers, and news consumers more broadly should be able to understand issues like spin and framing. On the other hand, however, we see a great deal of trouble in the ways that all media are, in these examples, conflated. It is unclear exactly who the students were talking about when they invoked "the media" in their responses. Students rarely identified which media outlets they were referring to as they described why they supported the president's statement or rejected it. A notable exception was present in this student's response, who stated, "I do think there are certain ... publications that are more biased than others, such as Breitbart or The Atlantic or the Onion or whatever." Beyond the rather surprising media outlets this student linked together as examples of biased sources, no other students specifically named "the media" they were thinking about when they responded to Trump's comments. The students have a misunderstanding about the media being a monolithic institution deserving mistrust.

In particular, the students who supported Trump's statement unequivocally - a group that comprises around a quarter of the students - did not make specific attempts to distinguish some media from others. This perspective is reflected in the response of one student who stated, "[The media] just take whatever [Trump] says and put it in whatever context they want to make their story, simply because they don't like him . . I'm also not concerned [about Trump's statement] because after the election, I don't really trust the mainstream media." Like the sentiments reflected by this student, the preservice teacher who 
supported President Trump's statement indicated that for them, "the media" and "the news" are entities with an identifiable and totalizing set of characteristics that have to do with ideological biases, partisanship, and nefarious intentions. "The media," in these articulations, functions as a catch-all phrase that represents an inherently flawed and untrustworthy set of texts.

About half of the students made attempts to distinguish between media that are untrustworthy and those that are not. This positioning is reflected in responses like one from a student who said: "I think it's just like anything and there are going to be some good ones and some bad ones." Another student signaled their ambivalence in a slightly more nuanced way: "I don't agree that the media are the most dishonest people on Earth. I feel that sometimes they truly do their absolute best to tell the truth. But at the same time, they are very biased." While the students who attempted to parse out problematic media from less problematic media did not name specific outlets, we see in their responses a clear attempt to classify media outlets on a continuum of trustworthiness - or at a minimum, to distinguish non-liars who are "trying to doing their best" from the liars.

One way to read the students' use of a generally monolithic notion of media across the responses to this task is to consider that the way the question was written and how that could have set them on a path to frame "the media" as a single entity. Neither in our question nor the president's statement is there a provocation to differentiate specific media outlets. We also did not ask them explicitly to consider the diverse types of media available from a single news resource. For example, we didn't encourage them to frame their response in terms of their perception of the opinion or editorial segments of a news source and their impressions of the regular beat reporters working for these news outlets. In that sense, then, we can think of students' monolithic framing of "the media" - both in terms of the idea that "the media" is a singular entity and that one news source can be characterized as trustworthy/untrustworthy without regard to the different types of "news" it produces - as a result of the way our prompt, and the president's statement, was worded.

Another way to read their description of the media in this context is to posit that it represents their conceptual conflation of media apparatuses and industry. For example, the student who reported that those working in media industries are "trained" to spin stories and events in certain ways is not entirely wrong. To be sure, there are those working in media industries whose tasks are to spin, convince, and shape. These are the people who work in public relations, advertising, and marketing. Journalists, however, are not trained in the art of spin. Rather, they are trained to analyze the spin and report their interpretations based on the widest range of information that can gather in a particular amount of time. People who are staff writers for newspapers and serious magazine publications (Harper's, the Atlantic, the Economist) are journalists. They are trained to analyze and present interpretations that serve the public interest.

Another category of media is the ideologically driven blog sites that position themselves as news, though they intentionally frame all stories to forward a predetermined, typically partisan, end. Those writing for such outlets may or may not be trained journalists. People who occupy a chair and host television programs on cable news networks or those who appear as commentators are in some instances trained journalists but are also 
often trained in broadcasting, public relations, and other fields that constitute their (hopeful) expertise.

All media institutions operate with different rules and are, to be clear, borne of starkly different disciplines and professional training: the distinctions are blurred often, but they are verifiable. While we see these differences as important distinctions, the nuances of this understanding may not be among the conceptual tools that students are bringing with them to their teacher education programs. In the assignment described here, as well as in others, most students made no attempt to differentiate their general distrust in the news media or to distinguish between news media outlets like Fox News from the journalists of the New York Times, the Guardian, and Washington Post-not to mention the ability to articulate the differences in journalistic integrity among the contributors to each of those outlets.

While we find this problematic, we recognize that the variability in the students' responses must be interpreted with complexity in mind. On the one hand, we do not mean to suggest that a sophisticated understanding of media would support the position that some media sources lack a bias. In fact, we would assert that sophisticated consumers of news media texts must be able to locate the bias present in all media. What these students' responses illuminated for us, then, is the importance of the nuanced understanding that not all bias is created equally. Further, these students' responses gave us insight into the complexity of recognizing that bias in media does not render a text untrustworthy, fatally flawed, or "fake." These insights are instructive in terms of the pedagogical challenges of media education in the dynamic context of current sociopolitical issues and events.

Other assignments, in which students were asked to think about and compare specific outlets and the value of using less and more reliable sources in their future teaching, offered more positive assessments of students' thinking about media. For example, in one assignment that we called "the media sort," students were given a list of about 20 wellknown news, television, and online media outlets. They were asked to place each outlet on a two-axis chart in which the $x$-axis was ideological positioning (left vs. right), and the y-axis was to represent their assessment of the integrity or trustworthiness of the source (trustworthy vs. untrustworthy). This assignment did not ask students to justify or explain their placement of media outlets in particular vectors and therefore did not provide the basis to assess the depth of their familiarity with the outlets on the list or their understanding of what makes an outlet trustworthy or not. Further, we did not ask students to reveal their own political ideology during this course, and thus cannot interpret their assignments in terms of their own political views. Despite these limitations, the assignment did provide the opportunity to evaluate the students' recognition of the existence of a range in ideology and credibility among media outlets. Overall, the students' performance indicated at least a cursory awareness of the scope of differences in ideology and credibility among media outlets on the list.

Additionally, all students placed at least some of the media outlets in the "trustworthy" quadrant. After completing this task, students were asked to comment upon whether or not they would ever use highly partisan, untrustworthy sources with their students. The following response is typical of the stance across their answers. This student explained that it is important to: 
Read the extremes because there are people out there who are reading these things. I think it is very important to be wary that you're not reading them away from other information, that you're reading them with things that are more trusted and maybe more toward the middle.

In the many responses like this one, we find evidence of preservice teachers' capacity to recognize the difference among media outlets. Further, we recognize their beginning efforts to imagine a particular kind of pedagogical encounter that would create an opportunity for their future students to differentiate between media sources.

\section{Interpreting assignments as complex articulations}

We draw on notions of complexity to arrive at two different but productive ways to frame these two assignments. First, the responses likely illustrate a phenomenon where students take up an assignment at the level of the register on offer. In other words, when we, as teachers, ask about "the media" in monolithic terms, then students respond in kind. When the assignments themselves position a more nuanced understanding, that understanding surfaces as well. These responses may indicate that when a pedagogical structure asks students to deploy their general understanding of bias, the complexities of media apparatus and industry tend to be masked. However, if the pedagogical structure is asking students to comment on finer-grained distinctions, they seem to be capable of doing so. When viewed in this way, it means we are foregrounding the subjective experiences of being a student. Rather than assuming that answers to questions on assignments are one-to-one representations of knowledge about media, here we are tasked with understanding them as simultaneously knowledge about media and knowledge about what to do on classroom assignments that are given by professors and doctoral students in their particular universitybased teacher education program. It calls our attention as teacher educators to the importance of being specific in our choice of language, questions, and assignments.

The students' responses to these tasks may also reflect the "mushy" operating knowledge that students bring with them to teacher education programs. By this, we mean that students' descriptions of media are blurry, inconsistent, and often contradictory in terms of what insight they offer about the ways they conceptualize and mobilize these media concepts in different contexts. These descriptions may signal the importance of creating multiple opportunities for students to explore and play with these ideas throughout their teacher preparation experience. When read in this way, then, we are foregrounding the specific nature of thinking about news media and what we think students know about it. We are compelled to acknowledge that because their academic backgrounds did not include formal introductions to media literacy or news media as a focal area of study, they have naïve understandings of it that (we think) are problematic and in need of addressing.

Misconception 2: even steven - the problem of false equivalence in understanding news bias False equivalence is, on a fundamental level, a rhetorical fallacy. It occurs in a wide variety of contexts and has a particular purchase in the format of cable news programming. The idea of false equivalence is that equal weight, time, and consideration are given to arguments or claims that are of unequal veracity. False equivalence is perhaps most clearly 
evident in the case of the issue of climate change and the practice of giving equal time to both an environmental scientist and a climate denier congressperson. While the former has expertise and grounds in empirical fact, the latter has neither or those but does have equal claim to time and, therefore, is seen as equally credible. This logical fallacy is a ubiquitous feature in our culture. For every story MSNBC runs about environmental degradation, FOX News runs one about how we can't be sure about the causes of climate change, if the climate if even changing at all. For many, this is a case example of two competing perspectives and therefore necessitating equal consideration. In an empirical sense, this need to balance attention is applied inappropriately to climate change. At the same time, it is critical to understand that ideological differences contribute to the understanding that climate change is a two-sided political issue in the United States.

All parties can only ever offer partial accounts. Media texts serve identifiable purposes and can be targeted toward different audiences. But that doesn't make all media resources the same. They are not co-equally biased. The same inclination that compels some actors to feel the need to give equal time to climate change experts and deniers, however, can vex social studies educators. By that, we mean to say that we seem to have boxed ourselves into a corner in social studies education. Scholars and practitioners in our field have fostered the understanding that including multiple perspectives in the curriculum is a "best practice." For example, structuring pedagogical engagements around competing interpretations of events, documents, and issues is a key aim of historical inquiry, which has risen to prominence in social studies pedagogy. While it is true that there are multiple perspectives and competing interpretations vying for favorable positioning within our current social and political landscape, it is not the case that each of those interpretations is equally valid. This recognition takes us to the second misunderstanding, which is the problematic understanding of bias and in particular, false equivalence, found in assignments related to media texts and pedagogy.

False equivalence reverberated through responses to a variety of prompts. The most concrete example arose in the previously described task that asked students to react to the January 2017 statement from President Trump about the dishonesty of the media. In the responses below, which are indicative of about half of the responses, we focus on how students work to construct and elucidate what functions as neutral or neutralizing positions.

I am both ways on this matter. I am concerned that he called them the most dishonest human beings on Earth. But there's some truth within what he's saying because media has such a bias and all media sources seem to like lean one way or the other.

I think that President Trump's comment might be a little bit extreme, but it's definitely not inaccurate ... I think that, in a way, the media can be very dishonest and there are certain aspects of it that are just awful . . . but I think in other aspects media can be really helpful.

Each of the above examples is an invocation of an implied sense of balance and a desire to have it both ways. There is such a thing as biased reporting. However, these responses 
illuminate the disposition to put two problems on an equivalent field and therefore neutralize whatever may be problematic about an issue: in this case, an inflammatory statement by the United States president.

Different mobilizations of false equivalence were found in another major course assignment, which asked students to track a major current events issue in two mainstream news media outlets over the semester. While we considered requiring the use of markedly biased news sources, we ultimately decided to allow students to choose from a set of media sources that employ professional journalists and were more likely to be categorized, overall, as balanced or fair (e.g., the Wall Street Journal, Washington Post, the Economist, National Public Radio [NPR], New York Times). In addition to summarizing the articles, students were asked if the writing was biased and, if so, to explain the bias present. The following student's response demonstrated the idea of false equivalence by invoking the ways that the New York Times was biased against Syria and Russia.

There is a very obvious bias shown in the publications that I am using to track the coverage of what is happening in Syria. The New York Times has repeatedly shown a bias against the Syrian government and Russia.

Here is an interesting instance in which the student does what a good student would: they found bias because they were asked to do so. However, this particular example represents a stunted understanding of bias. While the New York Times coverage of events in Syria may be "biased" in the sense of offering coverage that critiques a foreign power, their journalists are drawing on evidence to report on the parties who are persistently supporting massive acts of violence in a particular nation-state.

It could be tempting to view this student's response as an indication of ignorance, but complexity theory compels us to think in more nuanced ways about what is contributing to this student's interpretation of the Times coverage of Syria as biased against Syrian government and Russia. As Hetherington (2013, p. 78) asserted, to "achieve the richest possible picture of ongoing processes," it's necessary to map "interactions and feedback loops within complex systems." As such, we see that there are at least two different things at play here. First, it could be that because the student was asked to find and comment upon bias, they are doing so. This perspective foregrounds the complexity of being a student, as discussed above. The other, more nuanced phenomenon is to frame it as a discursive move toward an intended space of neutrality and objectivity. The student may see even-handed, two-sided description of events as the only way for the Times to occupy a fair, neutral, and unbiased space. Thus, in pointing to the lack of "both sides" perspective in the Times reporting on Syria, the student avoids "taking a side" on this conflict between Syria/Russia and the United States, and as such, occupies a neutral and objective space they may find both appropriate for teachers and personally desirable. To exemplify teacher candidates' desire to occupy a neutral space, consider the next example in which the student writes about the felt need to resist occupying a space that acknowledges a position.

My two publications are the New York Times and NPR; I went in assuming the NYT would be more liberal and NPR would be more center, but after reading 
some articles by some people, I would say they are both more left leaning. For example, a writer for the NYT, Coral Davenport, has covered many different articles having to do with the environment and the EPA. She was also featured in the Frontline global warming special we watched. In that special and her tone in the paper, she clearly does not agree with what Trump or the Republicans believe, and I do not recall seeing her put any positives (if any) about Trump's EPA decisions. While I do not argue with Davenport, I probably agree with her, but I do think there could be a better effort to being less biased in the paper.

What does it mean for this reporter to be less biased? It would, perhaps, mean occupying a seemingly neutral space that offers only an account of what different parties (the Trump administration on the one hand and the environmental science on the other) claim with no analysis or context to aid a readers' ability to comprehend the issue at hand. While "less-biased" approach may appeal to what the student senses is required for the fair and balanced presentation of the issues, it would be an abdication of the journalistic responsibility to serve as a check to power.

\section{Discussion}

Our hope in designing the pedagogical encounters that now serve as data in this paper was that we would be able to build students' critical capacities to engage with news media and their ability to think pedagogically about them. However, what we present here is a description and analysis of how their prior understandings served as robust and powerful narratives that were difficult to change in any observable way.

When considering the full body of students work on media over the semester, we see evidence of the pervasiveness, the power, the appeal, and the reach of the discourse that no media source should be trusted. This conclusion was particularly evident in the assignment that asked students to respond to Trump's comments about the dishonest media. In students' reactions to that statement, the message that the media cannot be trusted was deployed almost twice as often as the message that the press is fundamental to a democracy. This finding gives us pause. While this is one set of responses to one assignment, and therefore warrants a good deal of restraint in putting too much on the back of the evidence, it is not thin evidence. In fact, the articulation of views-in-the-making is crucial for teacher educators to examine in order to document the complexities of students' efforts to understand a dynamic process like the news media landscape. We can see, in moments of articulation, students' play with new ideas and attempts to put them to work with preexisting beliefs. We cannot know in advance what will happen to these ideas once the students have their own classrooms and students.

When thinking about how to best work with teacher candidates about media education, we must not assume that they are starting at "square one" or that our efforts to teach them about it can move them from A to B in a linear fashion. Rather, we must take into account that they have come to know about media without a formal pedagogical structure, rather as the lifelong recipients of an informal media curriculum. We can understand our students as coming to our program with well-formed ideas about media, learned by the 
pedagogies inherent in cultural living, just as they have learned about other issues like race (Garrett \& Segall, 2013). Our efforts in media education, just like in teacher education more generally, therefore involve a great deal of aiding in the reconstruction of old ideas rather than solely in the addition of new ones. This means exploring what students already think and feel about news media before introducing any supposedly "new" idea, knowledge, or teaching strategy. Educators should help teachers and students tolerate the highly complicated aspects of news media ecologies. Yes, news media outlets must get the attention of viewers and readers and therefore are prone to sensationalism. Yes, too, however, there are indeed more and less credible outlets that publish what we recognize as "news." Both things are true at the same time. Teacher education pedagogy appropriate to our current sociopolitical times requires further attention to these complicated processes.

\section{False equivalence as evidence of defense against anxiety}

We see false equivalence as a persistent feature of analysis of bias and, as discussed above, interpret the articulation of false equivalence as "move toward the middle." These moves toward neutrality indicate a naïve knowledge about media texts and the complexity inherent in recognizing that while all texts are incomplete representations, some representations are more credible than others. Sexias (2017) presented similar concerns about the proliferation of multiple perspectives, something about which social studies teachers and researchers have devoted significant attention, in a recent essay on history education:

Where does "positionality" leave knowledge in relation to the purveyors of "alternative facts," who claim they are the truth from their own position in Memphis or Moscow? Of course, people's varieties of experience and belief, and differences in relation to power and privilege, are at the core of the social, educational, and historical sciences. But building knowledge must ultimately emerge through dialogue, debate and discussion, as a common project conducted on a common basis of civility and with a shared respect for evidence.... Historians and history education scholars have welcomed the introduction of the personal and the local in recent years. Ironically, there is a parallel to the populist denigration of distant experts and cosmopolitan elites.

If teachers were experts in media studies and, in particular, news media, then they would be able to make claims about the differences between "expert-expert" debates and "expert-novice" debates like the one about climate change. What we see more commonly, though, are preservice teachers expressing desires to take a neutral, middle, objective position in relationship to anything that tinges of controversy or emotional cargo. It could be the case, we think, that rich experience in media literacy could aid in teachers' building confidence to structure these important pedagogical interactions (Kahne \& Bowyer, 2017).

However, this desire to occupy the middle position is also the position that makes intuitive sense for teachers to take in light of their vulnerability and their general position in the cultural imaginary. That is, perhaps another reason for preservice teachers' occupation of this space of so-called objectivity or neutrality is their worry about what will happen when conversations turn toward the controversial content that is inevitably part of discussions of 
current social and political issues. In elaborating this crucial aspect demanding the attention of teacher educators, it is:

No wonder public schools are emptied of the passion associated with an inspiring vision; those teaching in them are unable to carry a moral ideological torch. No wonder then that teachers are not seen as social or moral leaders but as individuals desperately trying to make a living while raising children, doing some extra jobs in the afternoon in order to pay the rent, possessing less education than some of their own students' parents. The public acknowledges the fact that teachers are soldiers without armor. Any passing spectator can take a shot, file a complaint, write a blog, send a talk-back, and add an insulting comment on Facebook. Under such circumstances, one cannot blame teachers for trying to find shelter in adopting "neutral" positions and adopting avoidance strategies-we give them very little choice. (Tamir, 2015, p. 129)

In other words, false equivalence that manifested in this classroom task points to a larger cultural problem that neither media education nor teacher education alone can possibly address. We see this acknowledgment as an underlying and ubiquitous feature of the imagination of teachers, particularly as they approach the most important (and therefore risky) issues facing students and the societies into which they are emerging. It could be, then, that the "running to the middle" we see in seeking this space of neutrality/equivalence is a symptom of these conditions of vulnerability, a defense against the dangers of engaging with content that can enliven passionate responses in students. Perhaps a prolonged engagement with media education and pedagogy can alleviate some of those anxieties, though they point to entrenched realities in the broader social and political landscape of their professional lives.

\section{Conclusions}

The topics described in this article emanated from our continuing inquiries into how preservice social studies teachers understand news media and current sociopolitical issues as we made pedagogical invitations to develop those understandings. Hetherington (2013, p. 77), contended that complexity-informed studies are "characterized by an openness to possibilities [and] the need to re-read and reflect on data from a range of viewpoints." Earlier, we illustrated our attempt to reflect on data from "a range of viewpoints" in order to contribute to a rich picture of the ongoing processes (Hetherington, 2013) that informed shaped students' responses to our news media lessons. In doing so, we describe the complications and limitations we found in our efforts: (1) that preservice teachers with whom we worked did not have a sophisticated understanding of news media, bias, and objectivity and (2) that we interpreted a reliance on invocations of false equivalence that we argue are layered with anxieties about neutrality and vulnerability. These misunderstandings simultaneously raise the stakes for teacher educators as well as call attention to the limits of teacher education concerning future teachers' knowledge of (in this case) news media. 
The assignments students completed during the semester reveal the complicated terrain of their orientation toward media and current issues as they relate to social studies pedagogy. But our students, like those in other studies capturing teachers' perspectives on media education, (Stein \& Prewett, 2009; Torres \& Mercado, 2006; Youngbauer, 2013) agree that social studies and media education are well aligned and teaching students about the news media and current issues (bias, credibility, etc.) is important. The support for media and current issues pedagogy in social studies was unanimous.

One place in which this support arose was in an end-of-the-semester assignment in which they were asked to describe their experiences engaging with media analysis over the term. All students remarked, to some degree, on the benefit and "goodness" of the assignment. These responses contained phrases describing the assignment as "cool," "great," "a pleasure," and "very interesting." No student indicated that learning about these topics was not beneficial.

What we end up with, then, is an interpretation of a situation in which students agree that there is important work to do related to news media literacy in their practice and yet do not possess the kinds of understandings needed in order to do that work. Part of what we think is important as teacher educators is to recognize and acknowledge the complexity of the phenomenon and in doing so, locate our students as preservice teachers who simultaneously acknowledge a need to provide a particular kind of awareness to their future students and report that they themselves do not have that same kind of awareness. We contend that has to do with the complex, overlapping manifestations of commitments, anxieties, and knowledge as they play out within the context of course assignment and in relationship to the tensions arising from the acknowledgment of the need to address that which is so crucially needed in formal schooling, namely supported attention into the big issues of our time and the ways in which we are positioned to understand them. After all, remember that there were articulations that were sympathetic to the notion that the press is "the enemy of the people." At the same time, the same students were vocal in their support for media education practices.

So what sense are we to make of this? On the one hand, we feel as though we can recognize some misunderstandings that students are bringing with them to their teacher education program around the topic of news media, bias, and credibility. With such recognition, teacher educators can pay more attention to building knowledge and practices with their preservice teachers that invite critical engagement with the news. There is an encouraging proliferation of materials and research about this very topic.

On the other hand, however, and in light of complexity theory, we are careful to acknowledge that what appears as "misunderstanding" of media bias might be better understood as a very well learned and well-formed, clear, understanding of media bias. What we mean is that growing up around prevailing discourses having to do with media bias (and race, gender, class, teaching, pedagogy, and so many other complex systems) entails learning clear lessons about what it is. Those lessons need to be brought from the realm of the implicit to the explicit curriculum (Eisner, 1994) and addressed as such.

We also need to invite preservice teachers to consider the ways that their views of media bias and their approaches to them in pedagogy are not just views about news media. They are also connected to their understandings of other complex phenomenon such as 
the vulnerability of teachers to parents' views, high stakes testing, conflict, and control in the classroom. In other words, what emerges almost immediately as an instance of false equivalence is simultaneously an instance of worry and, we feel, could be productively addressed as such. Complexity theory invites this kind of consideration between and among seemingly unrelated phenomenon.

Disclosure statement - No potential conflict of interest was reported by the authors.

\section{References}

Cochran-Smith, M., Ell, F., Ludlow, L., Grudnoff, L., \& Aitken, G. (2014). The challenge and promise of complexity theory for teacher education research. Teachers College Record 116(5), 1-38. https:// www.tcrecord.org ID Number: 17415

Damico, J. S., \& Panos, A. (2018). Civic media literacy as 21st-century source work: Future social studies teachers examine web sources about climate change. Journal of Social Studies Research 42(4), 345-359. https://doi-org.proxy-remote.galib.uga.edu/10.1016/j.jssr.2017.10.001

Davis, B., \& Sumara, D. (1997). Cognition, complexity, and teacher education. Harvard Educational Review 67(1), 105-126. https://doi.org/10.17763/haer.67.1.160w00j113t78042

Davis, B., \& Sumara, D. (2006). Complexity and education. Marwah, NJ: Lawrence Erlbaum.

Eisner, E. W. (1994). The educational imagination: On the design and evaluation of school programs. Macmillan Coll Division.

Garrett, H. J. (2017). Learning to be in the world with others: Difficult knowledge and social studies education. Peter Lang.

Garrett, H. J., \& Segall, A. (2013). (Re) considerations of ignorance and resistance in teacher education. Journal of Teacher Education 64(4), 294-304. https://doi.org/10.1177/0022487113487752

Hetherington, L. (2013). Complexity thinking and methodology: The potential of "complex case study" for educational research. Complicity 10(1/2), 71-85. https://doi.org/10.29173/cmplct20401

Iyengar, S., \& Hahn, K. (2009). Red media, blue media: Evidence of ideological selectivity in media use. Journal of Communication 59(1), 19-39. https://doi.org/10.1111/jcom.2009.59.issue-1

Jacobsen, R., Halvorsen, A. L., Frasier, A. S., Schmitt, A., Crocco, M., \& Segall, A. (2018). Thinking deeply, thinking emotionally: How high school students make sense of evidence. Theory $\mathcal{E}$ Research in Social Education 46(2), 232-276. https://doi.org/10.1080/00933104.2018.1425170

Journell, W. (2013). What preservice social studies teachers (don't) know about politics and current events - and why it matters. Theory \& Research in Social Education 41(3), 316-351. https://doi.org/ 10.1080/00933104.2013.812050

Journell, W. (Ed.). (2019). Unpacking fake news: An educator's guide to navigating the media with students. Teachers College Press.

Kahne, J., \& Bowyer, B. (2017). Educating for democracy in a partisan age: Confronting the challenges of motivated reasoning and misinformation. American Educational Research Journal 54(1), 3-34. https://doi.org/10.3102/0002831216679817

Kavanagh, J., \& Rich, M. D. (2018). Truth decay. RAND Corporation.

Kellner, D., \& Share, J. (2007). Critical media literacy, democracy, and the reconstruction of education. In D. Macedo \& S. R. Steinberg (Eds.), Media literacy: A reader (pp. 3-23). Peter Lang. 
McGrew, S., Breakstone, J., Ortega, T., Smith, M., \& Wineburg, S. (2018). Can students evaluate online sources? Learning from assessments of civic online reasoning. Theory \& Research in Social Education 46(2), 165-193. https://doi.org/10.1080/00933104.2017.1416320

Meehan, J., Ray, B., Walker, A., Wells, S., \& Schwarz, G. (2015). Media literacy in teacher education: A good fit across the curriculum. Journal of Media Literacy 7(2), 81-86. https://digitalcommons.uri .edu/jmle/vol7/iss $2 / 8$

Pariser, E. (2011). The filter bubble: What the internet is hiding from you. Penguin UK.

Schmeichel, M., Garrett, J., Ranschaert, R., McAnulty, J., Thompson, S., Janis, S., Clark, C., Yagata, S., \& Bivens, B. (2018). The complexity of learning to teach news media in social studies education. Journal of Media Literacy Education 10(2), 86-103. https://doi.org/10.23860/JMLE

Sexias, P. (2017, May 25). History educators in a new era. Public History Weekly 5(20), https://publichistory-weekly.degruyter.com/5-2017-20/history-educators-in-a-new-era/

Stein, L., \& Prewett, A. (2009). Media literacy education in the social studies: Teacher perceptions and curricular challenges. Teacher Education Quarterly 36(1), 131-148. https://www.jstor.org/stable/ 23479205

Stoddard, J. (2014). The need for media education in democratic education. Democracy and Education 22(1), 1-9. https://democracyeducationjournal.org/home/vol22/iss1/4

Sunstein, C. (2007). Republic.com 2.0. Princeton University Press.

Swift, A. (2016, September 14). Americans' trust in mass media sinks to new low. Gallup News. http://news.gallup.com/poll/195542/americans-trust-mass-media-sinks-new-low.aspx

Tamir, Y. (2015). Teachers in the social trenches: Teaching civics in divided societies. Theory and Research in Education 13(1), 121-136. https://doi.org/10.1177/1477878514566555

Torres, M., \& Mercado, M. (2006). The need for critical media literacy in teacher education core curricula. Educational Studies 39(3), 260-282. https://doi.org/10.1207/s15326993es3903_5

Wineburg, S., McGrew, S., Breakstone, J., \& Ortega, T. (2016). Evaluating information: The cornerstone of civic online reasoning. Stanford Digital Repository. http://purl.stanford.edu/fv751yt5934

Youngbauer, V. (2013). Application of media literacy and cultural studies in K-12 social studies curricula. The Social Studies, 104(5), 183-189. https://doi.org/10.1080/00377996.2012.722133

\section{Notes on contributors}

H. James Garrett (https://orcid.org/0000-0003-1674-1404) is an associate professor in the Department of Educational Theory and Practice at the University of Georgia. His research explores the emotional and affective dimensions of teaching and learning about complicated social and historical events. His book, Learning to Be in the World with Others: Difficult Knowledge and Social Studies Education, was published by Peter Lang in 2017.

Mardi Schmeichel (https://orcid.org/0000-0001-7765-7076) is an associate professor of educational theory and practice and affiliate faculty in Women's Studies and Qualitative Research at the University of Georgia. She researches news media literacy in social studies education, social media practices, and neoliberalism.

Sonia Janis is a clinical associate professor of social studies education at the University of Georgia, where she teaches preservice and in-service social studies teachers. Her areas of research include critical mixed-race studies and clinical practices in teacher education. To enhance the experiences of the pre- and in-service social studies teachers in her local community, she serves as a professor-inresidence with the Clarke County School District. 
Joseph McAnulty is a doctoral student of educational theory and practice at the University of Georgia. His research interests include political socialization, social media, news media literacy, and social studies teacher education. 